\title{
Numerical modelling calculation of probabilistic seismic hazard in cave mining
}

\author{
J Jarufe University of Santiago, Chile \\ J Wesseloo The University of Western Australia, Australia \\ Y Potvin The University of Western Australia, Australia \\ C Dhanér Linkdvist LKAB Kiirunavaara, Sweden
}

\begin{abstract}
Numerical modelling has been used for more than 30 years to assess the seismic potential in underground excavations. However, the outcome from modelling tools rarely considers the probabilistic nature of seismic hazards. This paper presents a method to generate a distribution of synthetic seismic data based on numerical modelling results. The distribution of this data follows an exponential model and can be utilized to perform statistical analysis of the largest magnitudes expected from the rockmass deformation due to underground excavations. This method is illustrated with a case study in a caving mine where the seismic potential is evaluated using a numerical model back-analysis exercise, resulting in the calculation of the exceedance probability of any seismic-event magnitude through the modelled period. The proposed method has an advantage over other methods that estimate seismic hazard because it implicitly calculates the statistical distribution of seismic events to obtain the exceedance probability of the largest event.
\end{abstract}

\section{Introduction}

Numerical modelling has been used for many years as a tool to evaluate seismic potential by simulating the physics that trigger seismicity. The physical mechanism that creates the rupture is called the source mechanism and even when several different source mechanisms have been defined (Ortlepp \& Stacey 1994), they can all be grouped into two basic rupture modes: those associated with fault slip shearing and those associated with high stress rock crushing (Ryder 1987; Gibowicz \& Kijko 1994). Numerical modelling has been developed over the last 30 years to simulate both basic rupture modes; however, these methods provide deterministic values of plastic deformation (assimilable to seismic event magnitudes) that do not represent the complete seismic hazard behaviour, which corresponds to a statistical distribution of the largest expected magnitudes for a specific rock volume within a defined time window.

Numerical modelling has been routinely used to assess seismic potential using different techniques. Some have focused on fault slip seismicity, such as the Excess Shear Stress (ESS) proposed by Ryder 1988, plastic displacement in fault planes as described by Potvin et al. (2010), Sjöberg et al. (2012), and Hofmann et al. (2012) or the use of finite elements to calculate plastic energy (DPE) as described by Beck et al. (2012). The rockmass crushing mechanism has also been covered with the Energy Release Rate (ERR) method described by Cook et al. (1976) and by Spottiswoode \& Miller (2002), or the Local Energy Release Rate described by Wiles (1998). All these methods provide an estimation of the seismic potential; however, they do not provide a hazard estimate because there is no probabilistic assessment of the results provided.

Beck \& Brady (2001) proposed a method to generate probabilistic analysis based on the ratio between seismic events above a specific magnitude and the total number of events within a specific range of modelled plastic results from numerical modelling (as Dissipated Plastic Energy DPE). However, no estimation of any seismic hazard parameter, such as the probability of exceeding a given magnitude, is provided. 
Explicit simulation of rockmass rupture (Board 1994; Mendecki et al. 2010; Jarufe 2019) has shown that it is possible to generate a distribution of fractures that generate a synthetic family of seismic events that follow the Gutenberg-Richter relationship; however, these methods require intensive computational power to simulate all the fractures needed to generate a proper frequency-magnitude relationship. This intensive computational requirement may limit the usefulness of this type of analysis for routine seismic hazard assessment.

The purpose of this paper is to introduce probabilistic calculations based on numerical modelling analysis without the complexities of explicitly including rockmass heterogeneities as asperities or joint sets that may considerably increase calculation times.

\section{Equivalent magnitude and probabilistic hazard}

Routine numerical modelling techniques described previously usually provide the total deformation associated with a modelled change in geometry. In the case of a multi-stage analysis, usually the total plastic deformation (or a derivate value) for each step is computed, representing all the displacement occurring during the modelled step. Aki \& Richards (2002) described the relationship between the seismic moment and the shear displacement $d$ taking place over the area $A$ as follows:

$$
M_{o}=G \cdot \int_{A} d d a
$$

Where $G$ is the shear stiffness of the rock mass, $d$ is the displacement at a point on a fault, and the integration is performed over the fault area $A$.

Hanks \& Kanamori (1979) describe a relationship to obtain magnitude from moment as follows:

$$
M=\frac{2}{3} \log \left(M_{o}\right)-6.1
$$

An equivalent instantaneous magnitude Me for any given mining step, defined as the magnitude of a single event with displacement equivalent to that accumulated throughout the mining step, can be defined by the following equation obtained by substitution of Equations [1] and [2]:

$$
\begin{gathered}
M_{e}^{i}=\log \left(\int_{A} d_{i} d a^{\frac{2}{3}}\right)+C \\
C=\frac{2}{3} \log \left(\frac{G}{1.413 \cdot G P a}\right)
\end{gathered}
$$

The Equivalent Magnitude calculated with equation 3 is based on the total deformation occurring during each simulated step. The rock mass deformation and associated seismicity, however, do not occur as a single large event, but as a population of events with a translated negative exponential distribution describing the distribution of magnitude, modelled as a linear relationship described by the GutenbergRichter (GR) relationship (Gutenberg \& Richter 1944). To generate this distribution of seismic data, the equivalent magnitude $\mathrm{Me}$ is decomposed into a set of smaller seismic events that distribute according to the GR relationship, generating an equivalent distribution De as shown in Figure 1.

Wesseloo (2020) pointed out that the relationship De shown in Figure 1, generally represented by the GR relationship, is a statistical model representing the size distribution of a population of seismic events and that this statistical model provides an avenue to perform probabilistic assessment of the seismic magnitude. For any given distribution De, the magnitude of the largest event that will eventuate is unknown but can be described by a probability distribution as shown in Figure 2 . 


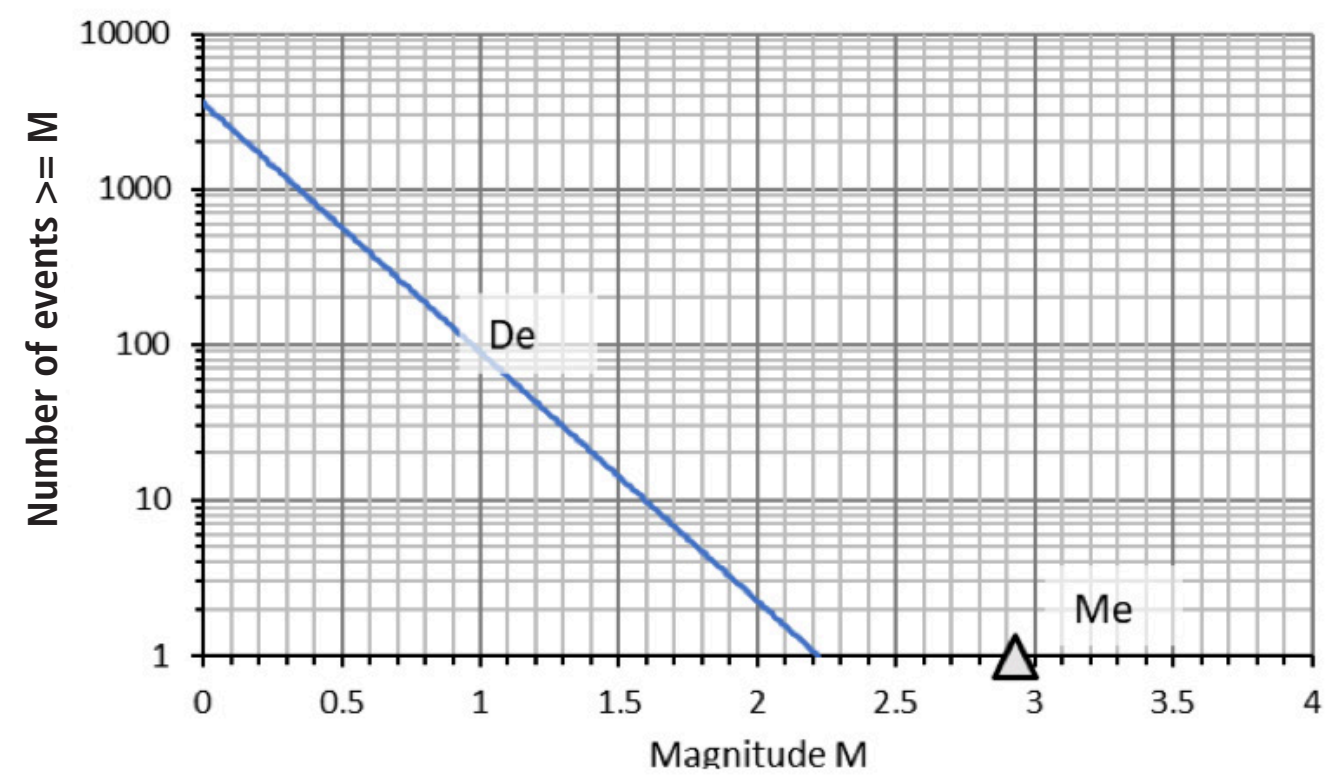

Figure 1 Equivalent distribution of seismic events (De) that generates the same seismic moment as the Equivalent magnitude ( $\mathrm{Me})$ as obtained from numerical modelling.

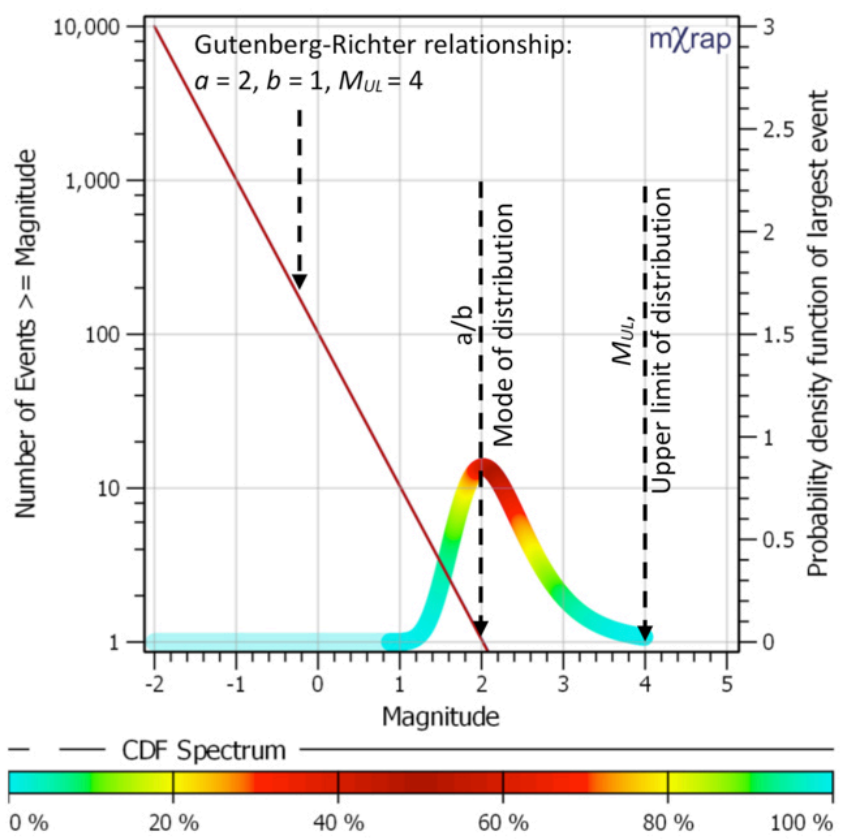

Figure 2 Frequency magnitude relationship and distribution of the maximum magnitudes (Wesseloo 2020)

The distribution of the magnitude of the largest event $f_{\text {MAX }}$ (Wesseloo 2020) defined as:

$$
f_{\text {max }}=n \cdot f(M) \cdot F(M)^{n-1}
$$


Where $\mathrm{n}$ is the number of events, $f(M)$ and $F(M)$ correspond to the density and cumulative functions of the Truncated GR relationship defined as

$$
f(M)=\left\{\begin{array}{c}
0, M<m_{\text {min }} \\
\frac{\ln (10) \cdot b \cdot 10^{-b\left(M-m_{\min }\right)}}{1-10^{-b\left(M_{U L}-m_{\min }\right)}, m_{\text {min }} \leq M<M_{U L}} \\
0, M \geq M_{U L}
\end{array}\right.
$$

and

$$
F(M)=\left\{\begin{array}{c}
0, M<m_{\min } \\
\frac{1-10^{-b\left(M-m_{\min }\right)}}{1-10^{-b\left(M_{U L}-m_{\min }\right)}}, m_{\min } \leq M<M_{U L} \\
0, M \geq M_{U L}
\end{array}\right.
$$

With b being the power law scale parameter used in the GR relationship (Gutenberg \& Richter 1944), $M_{U L}$ the upper truncation magnitude, $M$ is the magnitude and $m_{\min }$ the magnitude of completeness (Wesseloo 2020).

The use of an equivalent distribution De instead of a largest magnitude Me allows for the probabilistic assessment of the size of the largest events during different periods of mining. Model steps can be representative of different time scales, and the probabilistic results of each period need to be represented in the same time period. Normalization to any time period can be done using the equation proposed by Wesseloo 2020, where:

$$
P_{\mathrm{TN}}=1-\left(1-\mathrm{P}_{\mathrm{TE}}\right)^{\mathrm{TN} / \mathrm{TE}}
$$

where

$T N$ and $T E$ correspond to the normalized and original timeframes while

PTN and PTE are the equivalent probabilities for the TN timeframe and TE timeframe, respectively.

\section{Case study, back analysis in a sublevel caving mine}

The previously described method has been applied with an existing numerical model of the Kiirunavaara mine from 2011. The Kiirunavaara iron ore mine is one of the world's largest underground metal mines and is located about $150 \mathrm{~km}$ north of the Arctic Circle. The $4 \mathrm{~km}$-long orebody dipping $55^{\circ}-60^{\circ}$ to the east was mined using a sublevel caving method with $27.2 \mathrm{Mt}$ of iron ore products during 2019 (LKAB 2020).

At the time the numerical model was created, the mine was divided in sectors (Blocks) from 9 to 45, as shown in Figure 3. This case study is focused on Block 19 because it relates to a geologically and geometrically complex Block which experienced high levels of seismicity as the Block entered in production, generating several rock damage events (Woldemedhin \& Mwagalanyi 2010) and one fatality in February 2008 (Sjöberg et al. 2012).

Woldemedhin \& Mwagalanyi (2010) provide a description of the structural geology in the Kiirunavaara mine, pointing to the main characteristics as plastic shear zones in a North - South orientation, steep dipping to the east (structure group 4 in Figure 4), and brittle fault planes crossing almost perpendicular to the orebody (group 5 and 6 in Figure 4). 


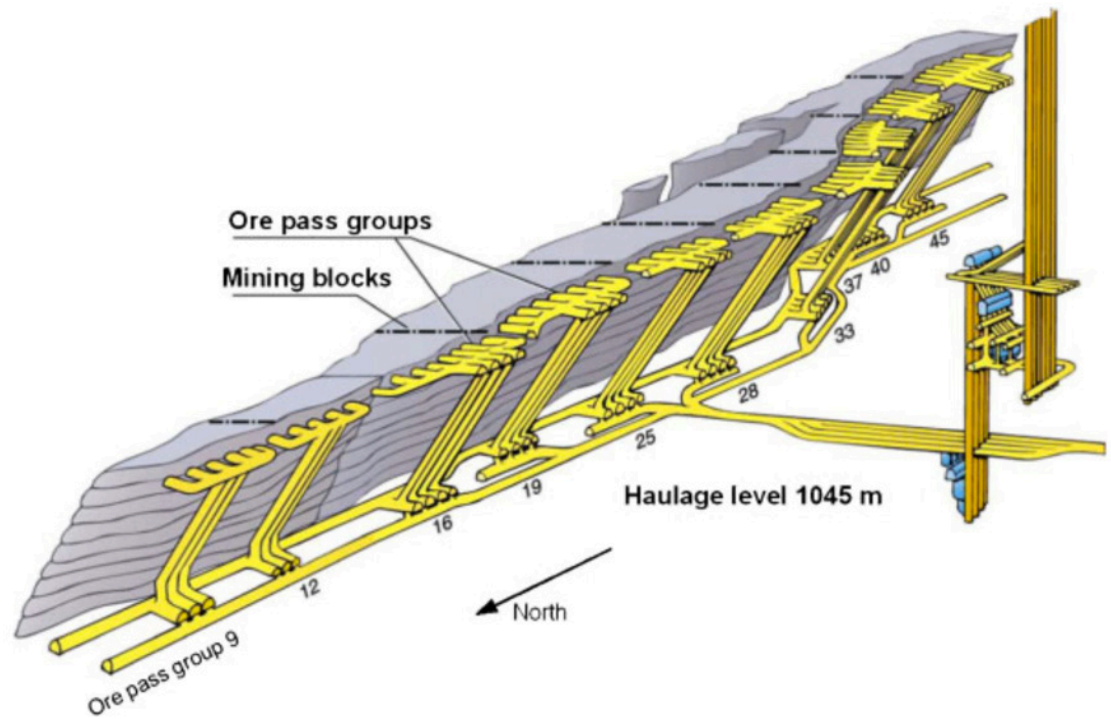

Figure 3 The Kiirunavaara mine orebody with different productive sectors (Sjöberg et al. 2012)

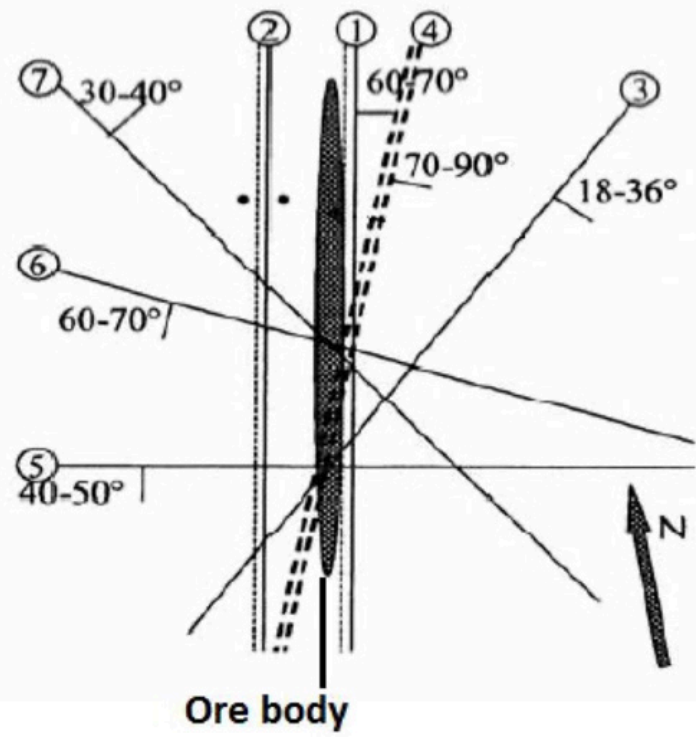

Figure 4 Main lineaments in the Kiirunavaara mine, with bold lines representing brittle fault planes and dashed lines representing plastic shear zones (After Woldemedhin \& Mwagalanyi 2010)

At the time modelling was done, the prevailing hypothesis was that Block 19's seismicity was dominated by sub vertical faults, perpendicular to the orebody, as shown in Figure 5, and it was in these faults that most of the seismicity was generated (in this block). This was supported by the analysis of the largest seismic events, rockfalls (Woldemedhin \& Mwagalanyi 2010) and seismic clustering around structures (Sjöberg et al. 2012) showing a shear-related source mechanism.

To simulate the seismic response of this zone, one fault plane representing all the fault planes in the seismogenic zone was built using MAP3D v6, and the excavation sequence was simulated through 2-month excavation steps from January 2009 to November 2010 (Figure 6). 


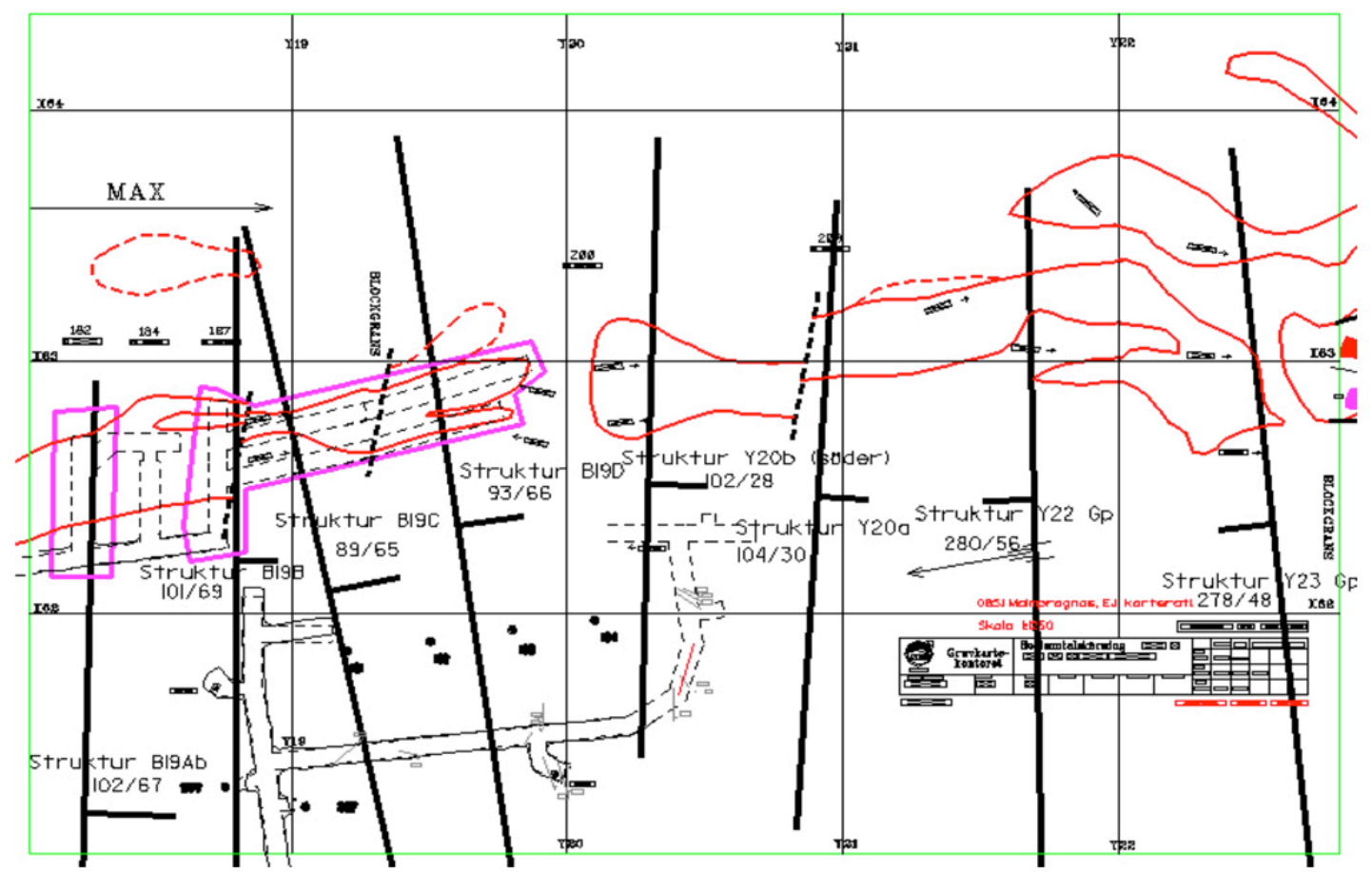

Figure 5 Orebody (red lines), principal structures (black coarse lines) and mining (dashed lines) in case study zone (Woldemedhin \& Hannington 2010)

Fault plane failure criteria were implemented through the Limit Equilibrium Strength (LES) method, described by Potvin et al. (2010) and Jarufe et al. (2012). This method assumes that the fault plane strength is at limit equilibrium with the pre-mining stress; therefore, any stress increment will trigger plastic displacement in the fault plane. The displacements obtained through this method are extremely high due to the low strength initially assumed for the limit equilibrium condition. However, to compensate for the large modelled deformations, calibration with past seismicity was utilized to generate a calibration factor (process described in Potvin et al. 2010; Jarufe et al. 2012). In the situations where no previous seismicity exists, seismological analysis has concluded that approximately $15 \%$ to $30 \%$ of fault-plane areas are actually generating co-seismic displacement, with the rest of the fault acting like an aseismic patch, i.e. a barrier, or as a soft zone between asperities (Aki 1984) that creep without generating seismicity. In this case study, existing seismic data have been used to calibrate a MAP3D model with a plastic fault plane using the LES criteria previously explained. The model included 13 excavation steps from January 2009 to November 2010.

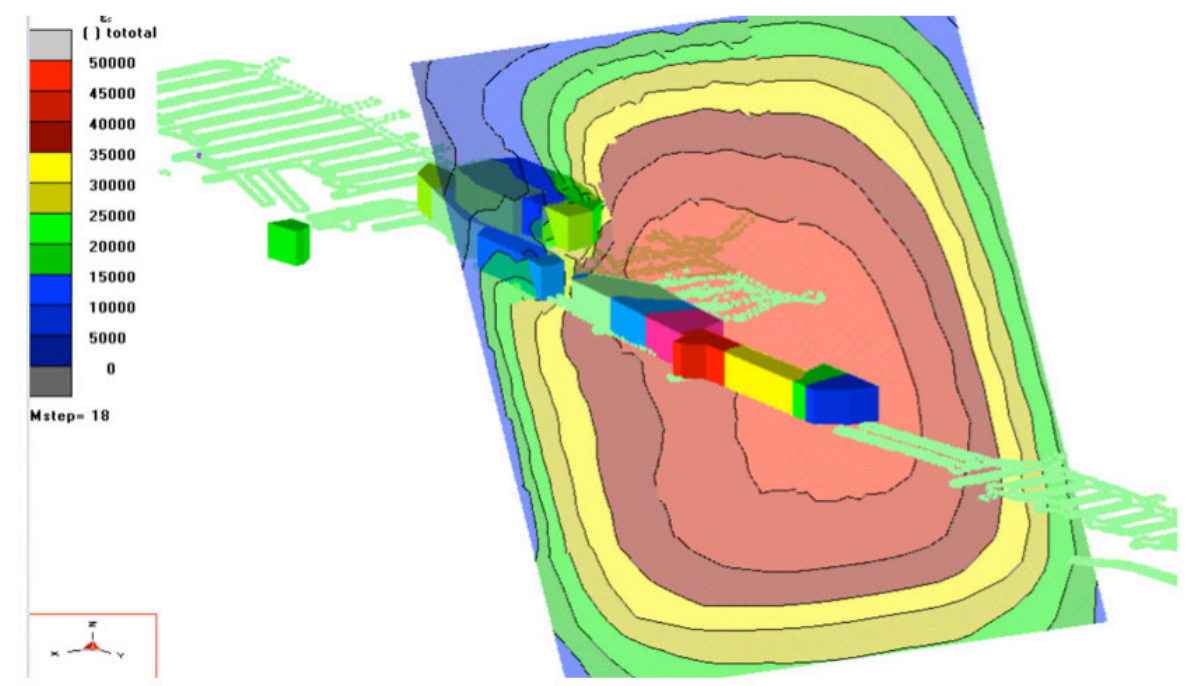

Figure 6 MAP3D model with block 19 blast sequence and a generic fault representing the possible fault sets existing in this zone 
Once plastic displacement was computed in MAP3D, seismic moment was calculated using the relation proposed in the Aki 2002 Equation [1] representing the total deformation occurring during each simulated step, in this case 2 months. A good correlation was obtained between the modelled and recorded seismic moment and a calibration factor of 0.15 was obtained by minimising the difference between the modelled and recorded cumulative moment, i.e.:

$$
M_{o} \approx 0.15 \cdot M_{o}^{\text {modelled }}
$$

The results from the correlation are shown in Figure 7, in which the general trend in seismicity is well captured; however, in July 2009 the model overestimated displacements and the seismic moment. This discrepancy may be related to the assumptions made in the modelling regarding fault-plane orientation and strength. When comparing the modelled and measured seismic moment, the absolute difference is $12 \%$, for all excavation steps, when calibration is performed considering all excavation steps.

Because the model was calibrated with all the seismic data, there was no time window to evaluate the forecast performance of the model. In this regard, the model is used as an exercise to evaluate the model capability to represent the observed seismic behaviour in fault zones.

After model calibration, the Me and De were calculated as described in Section 2, Equation [3], and using the theoretical framework presented in Section 2, and equation 5, the density function of the largest magnitudes can be calculated. Based on this distribution, an exceedance probability (showing the probabilistic nature of the maximum magnitude distribution) was calculated. The relation that describes the statistic distribution of the maximum value was implemented using the geotechnical analysis software mXrap (Harris \& Wesseloo 2015), where the distribution of magnitudes for each modelled step was calculated and expressed as the exceedance probability in Figure 8. This represents the probability of a seismic event larger than a magnitude $M$, occurring within a two-month period. An MUL magnitude value of 4 was chosen considering a conservative value; however, several methods to calculate this value exist and are described by Wesseloo (2018).

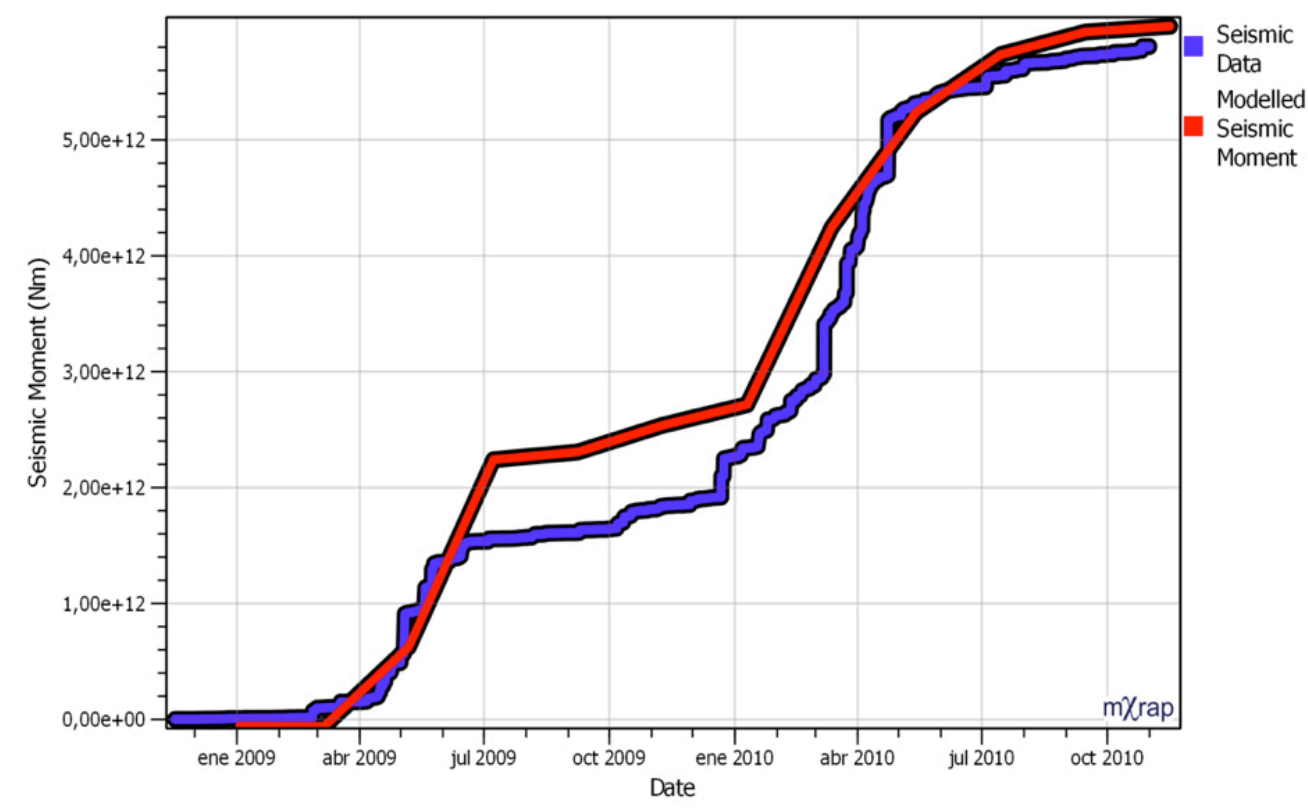

Figure 7 Comparison between all modelled seismic moments and observed seismic data (plotted as cumulative seismic moments) 
Figure 8 shows the probability of exceeding a specific magnitude (vertical axis) as a colour scale for a specific excavation stage (bottom axis). In this case study, modelling results show that in July 2009 there was a $50 \%$ probability of experiencing a magnitude equal to or greater than 1.9 and a probability of $5 \%$ of a seismic event with a magnitude 3 or more. Also, an increase in the probability of experiencing large seismic events was estimated for the months July 2009 and March 2010.

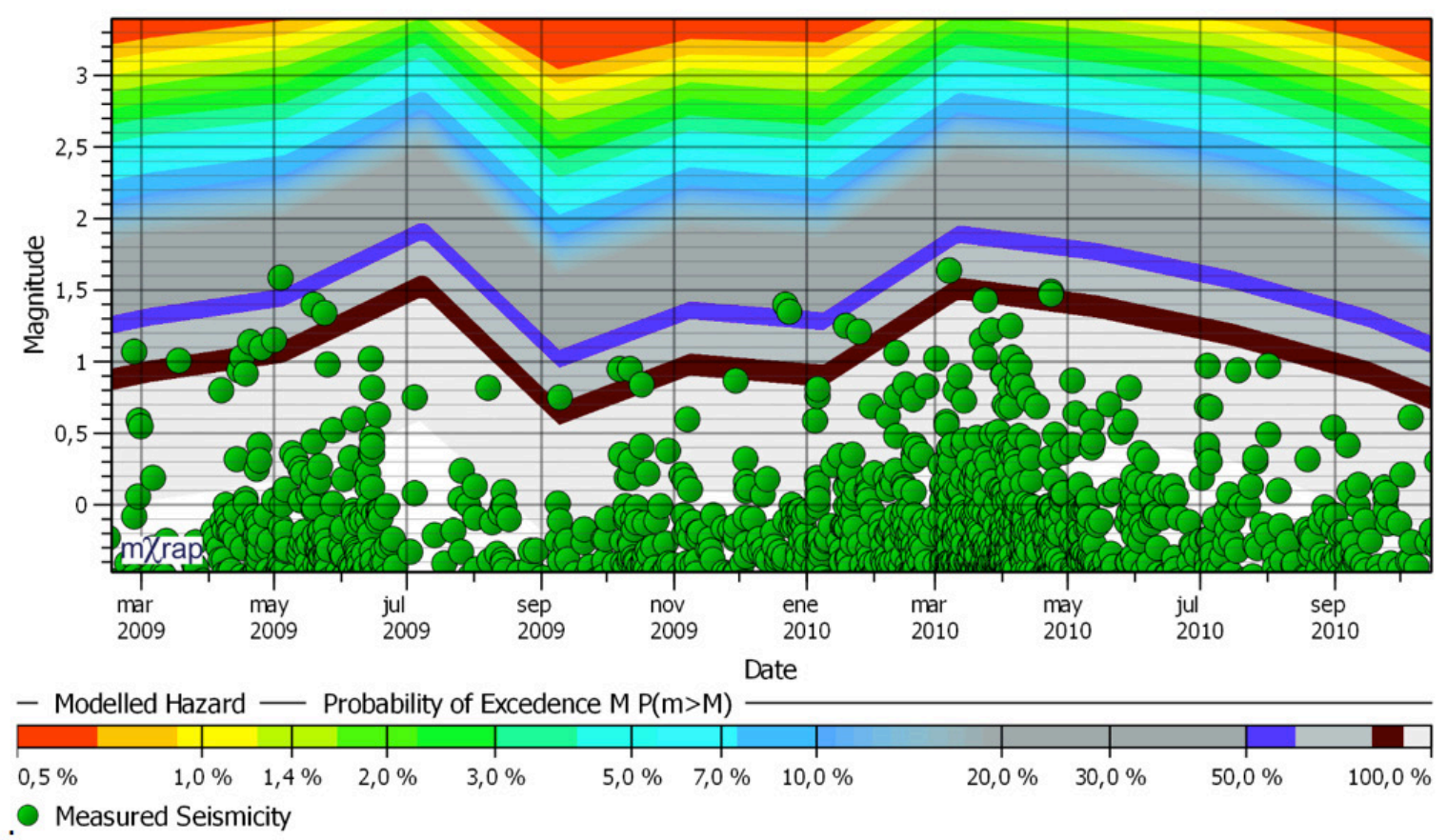

Figure 8 Colour scale representing the seismic hazard as the probability of experiencing a seismic event greater than M. Real seismic data are plotted for comparison

The probabilistic results observed in Figure 8 can be projected onto a specific magnitude, calculating the exceedance probability at each modelled step. These results can be annualized using equation [8] (Wesseloo 2020) to obtain the annualized probability of experiencing a seismic event. The case shown in Figure 9 is the probability of experiencing a seismic event of a magnitude greater than $\mathrm{Mw}=3$.

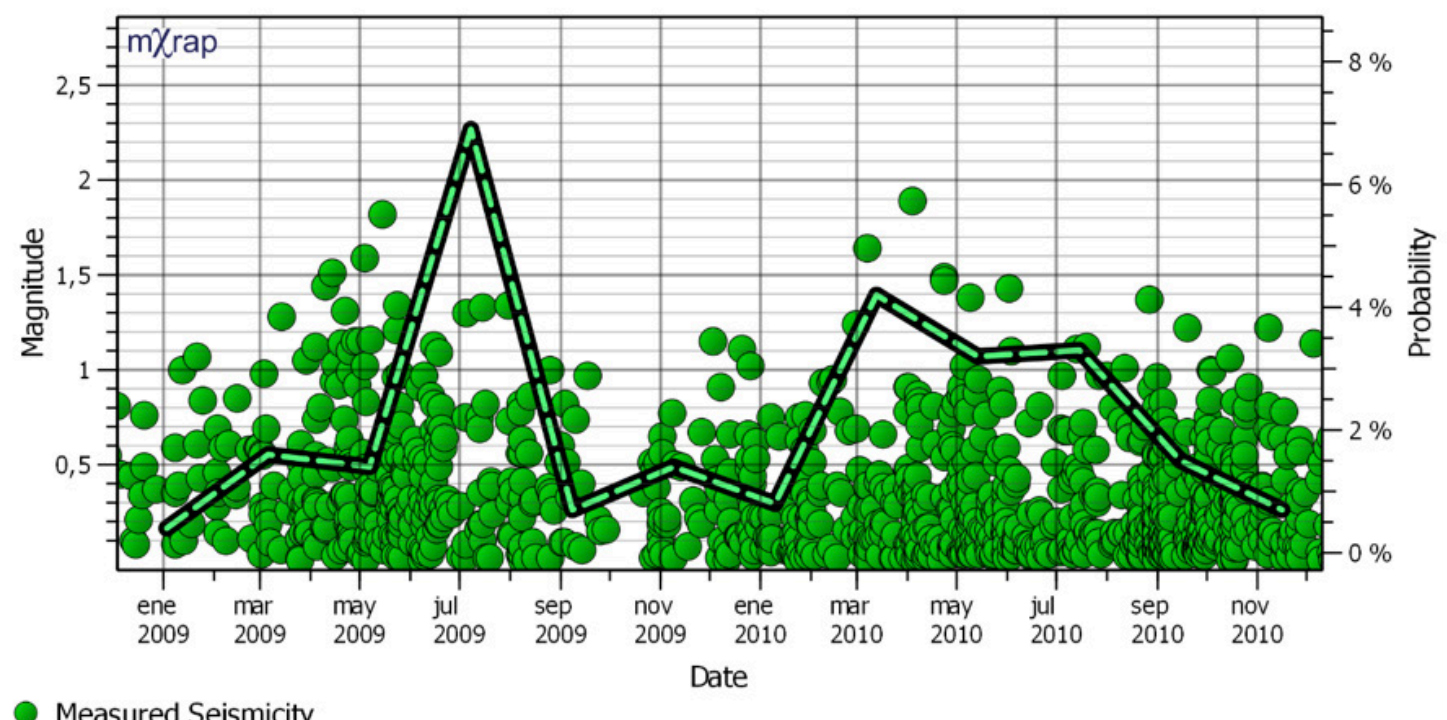

Figure 9 Real seismic data and modelled annualized probability of exceeding a magnitude Mw $=3$ seismic event 


\section{Discussion}

The proposed method allows the calculation of seismic hazard based on the probability of exceeding a specific magnitude at a specific date in a given zone (in this case, a fault plane). These calculations are based on commonly used numerical methods to estimate plastic displacements in faults and in the rock mass near underground excavations. Based on these results, a synthetic distribution of seismic events can be generated and utilized to perform statistical analysis. The statistical analysis allows the estimation of the probability of experiencing a seismic event above a specific magnitude in a specific time period (using equation [8], time normalization), in a specific fault plane. The proposed method has an advantage over other methods that estimate seismic hazard because it includes the probabilistic nature of seismicity in the results. This is an improvement over numerical methods that do not consider this parameter in the calculations.

\section{Conclusion}

A method to assess seismic hazard has been proposed based on numerical modelling and the decomposition of the modelled displacement according to an exponential distribution i.e. the GutenbergRichter relationship. This decomposition and exponential distribution allows statistical analysis based on modelled results that provide quantitative measurements of future seismic hazard for mine sequences.

In the case study developed in this work, the probability of exceeding any magnitude is plotted along with a specific time history with the probability of exceeding magnitude 3 .

The proposed method provides an advantage over other methods that estimate seismic hazard because it includes the probabilistic nature of seismicity in the estimation of the largest magnitudes.

\section{Acknowledgement}

The authors would like to thank the Universidad de Santiago for funding this research, LKAB Kiirunavaara mine for permission to publish this research, MAP3D International for providing software licences for this study derived from doctoral research, and the mXrap Consortium for providing software support during the development of this project.

\section{References}

Aki, K \& Richards, P 2002, 'Quantitative Seismology', Second Edition, University, Science Books, California.

Aki, K 1984, 'Asperities, barriers, characteristic earthquakes and strong motion prediction', Journal of Geophysical Research, 89(B), 5867-5872,http://doi.org/10.1029/JB089iB07p05867.

Beck, DA Levkovitch, V \& Simser, B 2012, 'Explicit discontinuum simulation for probabilistic forecasting of fault slip and rockmass seismic potential', In Deep and High Stress Mining, The Australian Centre for Geomechanics.

Beck, DA \& Brady, BHG 2001, 'Evaluation and application of controlling parameters for seismic events in hard-rock mines', International Journal of Rock Mechanics and Mining Sciences. Editorial reference: 2002/002093.

Beck, D, 2000, 'A method for Engineering Management of Induced Seismicity in Deep-Level Hard Rock Mining', Ph.D. Thesis, University of Queensland, Australia (unpublished).

Cook, NGW 1976, 'Seismicity induced by mining'. Engineering Geology, vol 10, pp. 99- 122.

Gibowicz, SJ \& Kijko, A 1994, 'An Introduction to Mining Seismology', San Diego: Academic Press, ISBN: 0-12-282120-3.

Gutenberg, B \& Richter, CF 1944, 'Frequency of earthquakes in California', Bulletin of the Seismological Society of America, vol. $34,185-188$

Harris, PH \& Wesseloo, J 2015, 'mXrap software', version 5, Australian Centre for Geomechanics, The University of Western Australia, Perth, Western Australia, http://mxrap.com/. 
Hanks, TC, \& Kanamori H 1979, 'A moment magnitude scale', Journal of Geophysical Research, 84, 5, 2348 - 2350, 9B0059, doi:10.1029/JB084iB05p02348.

Hudyma, M 2010, 'Applied Mine Seismology Concepts and Techniques', Technical notes for ENGR 5356- mine Seismic Monitoring Systems, Laurentian University.

Jaeger, JC \& Cook, NGW 1979, 'Fundamentals of Rock Mechanics 3rd ed', London: Chapman and Hall, ISBN: 0-412-22010-5.

Jarufe Troncoso, J, Potvin, Y \& Wesseloo, J 2012, 'Application of the limit equilibrium strength to the seismic assessment of shear related seismicity', Presented at the Sixth International Seminar on Deep and High Stress Mining, pp. 389-400, https://doi.org/10.36487/ACG_rep/1201_28_juan.

Larsson, K 2004, 'Mining Induced Seismicity in Sweden', Licenciate Thesis, Luleå University of technology.

LKAB 2020, 'End Year Report 2019', LKAB Press Reports 2019.

Ortlepp, WD \& Stacey, TR 1994, 'Rockburst Mechanisms in Tunnels and Shafts. Tunnelling and Underground Space Technology', vol 9, no. 1, pp 59-65

Potvin, Y, Jarufe, J \& Wesseloo, J 2010, 'Interpretation of seismic data and numerical modelling of fault reactivation at El Teniente, Reservas Norte sector', Mining Technology. vol. 119, pp. 175-181, https://doi.org/10.1179/17432861 0X12820409992453.

Ryder, JA 1988, 'Excess shear stress in the assessment of geologically hazardous situations'. Journal of the South African Institute of Mining and Metallurgy, vol 88, no.1, pp 27-39.

Sjöberg, J, Perman, F, Quinteiro, C, Malmgren, L, Dahnér-Lindkvist, C \& Boskovic, M 2012, 'Numerical Analysis of Alternative Mining Sequences to minimize Potential for Fault Slip Rockbursting', Mining Technology vol. 121, no.4, pp. $226-235$.

Spottiswoode, SM \& Miller, AM 2002, 'A Methodology and Computer Program for Applying Improved, Inelastic ERR for the Design of Mine Layouts in Planar Rifts', SIMRAC Final Project Report, GAP 772.

Wesseloo, J 2020, 'Addressing some misconceptions regarding seismic hazard assessment in mines', The Southern African Institute of Mining and Metallurgy, vol 120, pp. 67-80.

Wesseloo, J, 2018, 'The Spatial Assessment of the Current Seismic Hazard State for Hard Rock Underground Mines', Rock Mech Rock Eng 51, 1839-1862, https://doi.org/10.1007/s00603-018-1430-4.

Woldemedhin, B, \& Mwagalanyi, H 2010, 'Investigation of Rock-fall and Support Damage Induced by Seismic Motion at Kiirunavaara Mine', Master of Science in Engineering Technology, Lulea University of Technology. 